\title{
COMMUNICATION TOOLS FOR INACCESSIBLE PLACES OF SIGNIFICANCE
}

\author{
P. Hallot ${ }^{1 *}$, M. Lambert ${ }^{2}$, P. Jouan ${ }^{1}$
}

\begin{abstract}
${ }^{1}$ DIVA, Art Archaeology Heritage University of Liège, 4020 Liège, Belgium (pjouan, p.hallot)@uliege.be
${ }^{2}$ Alumni of the Faculty of Architecture, University of Liège, 4020 Liège, Belgium marie.lambert@alumni.uliege.be
\end{abstract}

KEY-WORDS: heritage communication, phygital heritage, projection mapping, digital built heritage.

\begin{abstract}
:
This article deals with the communication of inaccessible heritage. Based on a classification of different mediation tools, we propose a framework for selecting the most appropriate tools to communicate about heritage sites under restoration and, therefore, inaccessible. Furthermore, from the data already collected, we show how it is possible to use the constraints of building sites as opportunities for mediation. Finally, we apply this scheme to the case of the collegiate church of Sainte Croix in Liège, for which we end up proposing three mediation tools: the creation of a virtual visit website, the realization of 3D printed scale models, and the design and printing of a cover sheet showing the interior of the building at $1 / 1$ scale.
\end{abstract}

\section{INTRODUCTION}

Knowledge about the history of heritage sites inform and shape interpretations about their cultural significance. Along with the evolution of the heritage discourse, experts centred approaches, mainly considering the significance of places as an intrinsic quality of their historical fabric, have given way to more inclusive perspectives which recognize a wider range of values, like the social value of heritage for instance (Buckley, 2019). Current practices attempt to capture the interpretations of all stakeholders sharing interests in the conservation of a place to approach the assessment of its significance (Avrami \& Mason, 2019). Heritage values are linked with historical features based on information associated with historical events, personal experiences, or even emotions. These values attached to things vary across time and depend on the society in which they are defined (de la Torre, 2013). Therefore, conservation relies on the enhancement and transmission of the knowledge associated with heritage objects. In addition, many activities communicate about heritage in general, starting from the touristic application where people come physically to a site for a visit. Another crucial mediation support for heritage is all the production of heritage representation. Each map, plan, sketch, 3D model, or virtual environment supports a mediation of heritage. Some of them are more dedicated to communication and mediation purposes. However, they all support a general knowledge level of the objects they represent.

Usually, a lot of communication is organized around a heritage building before its rehabilitation. Such mediation, which allows to raise awareness and involve the various stakeholders in the research of investors, in the quest for new uses, as well as in the elaboration of conservation projects and management plans, is the synonym for continuous and intense communication about the project. However, during the completion of conservation and restoration works, it is frequent to observe a long period of inactivity in terms of communication and knowledge diffusion. In some cases, the lack of interest in heritage sites leads to some general forgiveness where the link between people and heritage objects fades, and the strength of associations between features and aspects of value tends to decrease. Therefore, continuous communication about heritage is interesting before and during the rehabilitation projects, which can sometimes last for decades.
This research proposes adapting the Phygital Heritage framework to guide the choice of appropriate communication methods and tools when heritage sites are not accessible for an extended period. This article further discusses the implementation of such framework on a practical case study, namely the Collegiate Sainte Croix of Liège (Figure 1), Belgium. The choice of this project is motivated by our collaboration with the consortium in charge of the rehabilitation of the building, in which our role was to support experts in the mediation of the work.

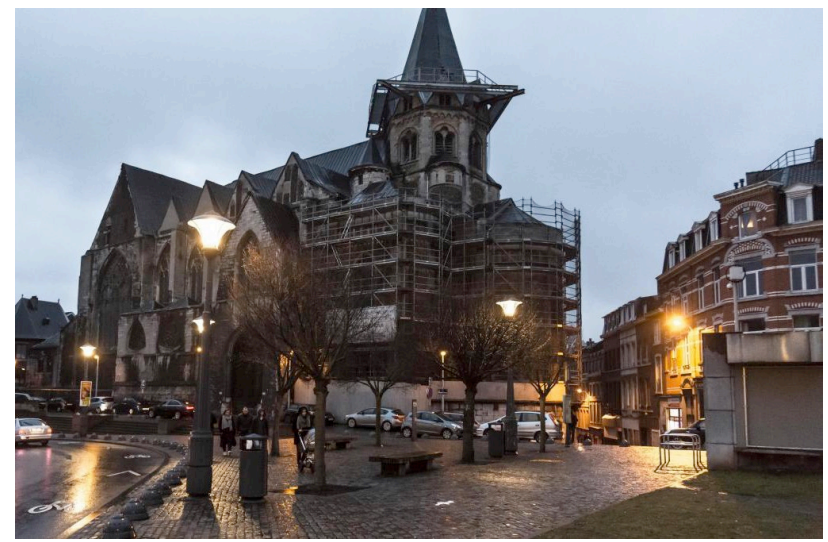

Figure 1. View from the collegiate church Sainte Croix of Liège, Belgium (C M. Lambert).

The Collegiate church Sainte Croix of Liège is one of the most salient buildings in the city of Liège. Erected between 976 and 986 by Bishop Notger and located close to the city's historical centre, the church houses the key of Saint Hubert, formerly in the treasury of the collegiate church of Saint-Pierre in the same city. After the Liège Revolution, the chapter of canons was abolished in 1797 , but the church was returned to worship in 1802 . Protected by law in 1936, it was included in the list of exceptional heritage of the Walloon Region in 1971. In October 2013, it was included in the list of 67 monuments in danger established by the World Monuments Fund. The building is $57 \mathrm{~m}$ long, $25 \mathrm{~m}$ wide, and has a vaulted height of $17 \mathrm{~m}$ in the main nave. It is one of the seven collegiate churches of Liège (Saint-Pierre, Sainte-Croix,

\footnotetext{
Corresponding author
} 
Saint-Paul, Saint-Jean, Saint-Denis, Saint-Martin, SaintBarthélemy) (Piavaux, 2002). Due to its dilapidated state, the church has been closed to the public since 2005. This situation is particularly regrettable given the prominence of the church in the urban scape and historical development of Liège and considering its significance and multiple recognitions at regional and international levels

The total cost of the restoration and rehabilitation work is estimated at over 20 million euros. It is essential to note that these works are planned to last for about ten years. Indeed, they began in 2017 with preliminary studies and should be completed in 2026. This inaccessibility period to the public must be added to the building's last ten years of closure for security reasons. In total, no less than twenty years of continuous inaccessibility of the site will be experienced by the public. Therefore, it is easy to see how important it is to ensure continuous communication to maintain a link with such an investment. Otherwise, the public may not correctly balance the high values of such a place with the investment realized by the community.

It is worth mentioning that this research was initiated from the master thesis of Marie Lambert (Lambert, 2020).

The rest of the paper is structured as follows. First, we will give a general vision of communication tools in heritage. Then, we show that the images computed from surveys are not neutral and can support interpretation, sensitivity, etc. Next, chapter 3 presents the extension of the Phygital heritage classification by including communication tools dedicated to inaccessible heritage places. Finally, we apply the proposed framework to the case of the Collegiate Sainte Croix church in chapter 4. Then we conclude and propose research perspectives.

\section{STATE OF THE ART}

The post-war period has placed us in a trend towards democratizing culture (Gattinger \& Whitehorse, 2011). As a result, heritage has become a source of value and wealth. Accordingly, the government has been keen to make it accessible to a broad public, whether through financial means or education (Evrard, 1997).

Much research has been carried out on the representation and perception of heritage elements. Among those, we would like to point out the ones that contribute to preserving the link to the buildings, to our perspective. Distinguishing the matter and the image of works of art, Brandi argues that the former act as a medium allowing the latter to be (re)produced in the individual consciousness of the observing subject. The spatiotemporal continuity of the physical realm of places allows the present observer to (re)interpret its meanings (Brandi, 1963). As indirectly indicated in the previous statement, such phenomenon is related to objects' perception.

Several authors reflected on the experience of architectural works. More than in other arts, the observer needs to physically explore a site (Choay, 1999) to appreciate its qualities, understand its meanings and develop a sense of the place. Bader discusses the key aspects of this phenomenon related to the subject, the object itself, and other intangible mediums intervening in the perception scheme such as light and shadows, people flows, etc. (Bader, 2015). He proposes a model synthesizing the scheme of perception of the architectural context in everyday life from the individual's perspective. Considering the particularity of the architectural experience and the solid educational dimension of cultural heritage, guaranteeing accessibility to places of significance for the public appears crucial.

Nevertheless, heritage sites may become inaccessible for numerous reasons. In this case, traditional and emerging communication tools provide an alternative to disseminate knowledge about non-reachable or experienceable heritage (Barazzetti et al., 2015; Caspani et al., 2017; Hausmann \& Weuster, 2017; Pantano \& Tavernise, 2009; Pybus et al., 2019). However, considering the wide variety of tools and techniques that can be implemented in such a framework, it appears essential to question their efficiency and pertinence depending on the projects' objectives and the nature of the site itself, the targeted public, etc. (Garcia-Fernandez \& Medeiros, 2019).

Highlighting the growing convergence of the physical and digital worlds, as witnessed, for instance, by the emergence of the Internet of Things, Nofal suggests adopting digital information communication tools based on physical representation and tangible user interface. He indicates that although some built heritage values are related to factual and explicit knowledge, other meanings and value judgments are more difficult to communicate because of their tacit and abstract character (Nofal et al., 2018). Based on research in educational psychology, Nofal argues that interaction with tangible objects or interfaces facilitates the understanding of the rather implicit knowledge of the built heritage. He proposes a classification system for communication tools to distinguish different levels of "phygitality". According to Nofal, Phygital heritage designates the tools integrating "digital technology" into "physical reality" (see figure 2).

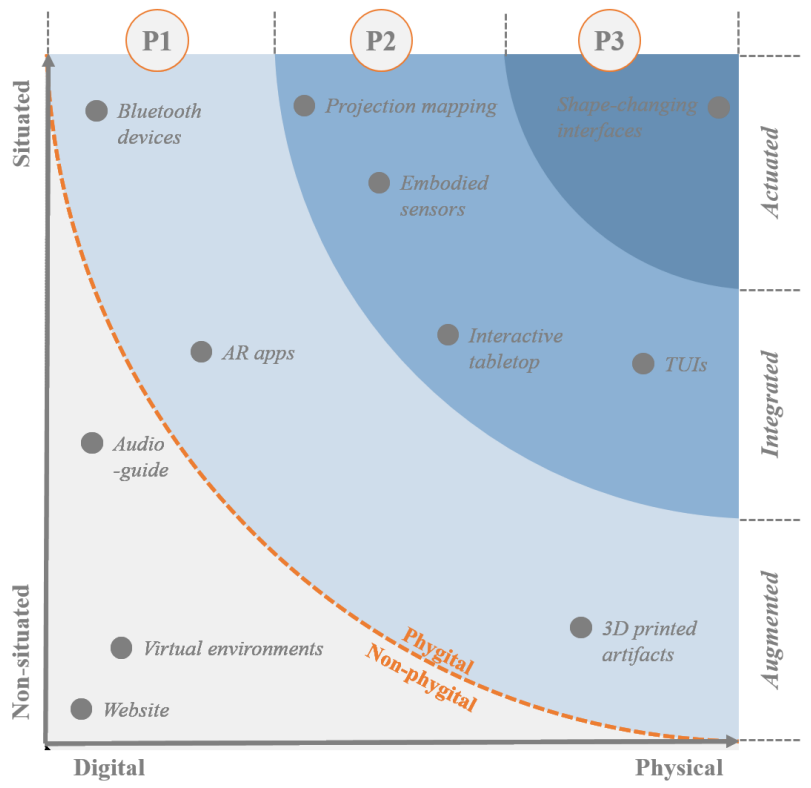

Figure 2. Phygital Heritage classification (from (Nofal et al., 2017)).

The model takes two variables into account to determine the position in the Phygital Heritage scheme. First, the tool is evaluated regarding its physical affordance. Secondly, their situatedness is evaluated. The affordance, referring to the possibility of actions offered by ICT tools to end-users, is a key aspect impacting the "efficiency of information retrieval" for rather abstract data. The other dimension of the graph queries the actual level of integration of the implemented digital technologies in physical reality. The latter allows determining how the transmission of the information depends on the physical context in which it is situated to be understood. Examining ICT tools from this dual perspective, the model allows distinguishing phygital techniques from non-phygital and identifying different categories of Phygital heritage (Augmented, Integrated \& Actuated). 
In the following, we look at several means of communication associated with heritage. For each of these, a salient example has been selected to provide a broad range of possible achievements.

\subsection{Facsimile}

The virtual reality project dedicated to Lascaux was carried out by Ateliers des Fac-Similés du Périgord (AFSP) for three years. They reproduced a complete replica of the decorated caves of Lascaux discovered in 1940. Weissberg writes about the site's closure in 1963 due to the appearance of 'green spots' on the walls. The deterioration was due to the massive presence of the public, which increased carbon dioxide and created moss (Weissberg, 1999). The site was therefore closed to the public to preserve it. In 1983, a physical copy of the cave called "Lascaux II “was created. In the late 2010 s, based on the visit's success, a temporary exhibition was created and travelled across the world. The Lascaux IV project developed by the AFSPs continues this trend and represents the site in its entirety (see figure 3). A space of $8000 \mathrm{~m} 2$ welcomes visitors and allows them to contemplate the cave. The installation is in the Centre International de l'Art Pariétal in the Dordogne at the foot of the Lascaux hill. Images projecting Lascaux into the past are shown to retrace the history of the cave, and a room allows visitors to walk through a life-size reproduction of the cave. The atmosphere has also been reproduced: the temperature, acoustics, and lighting are almost identical to the original (Bader, 2015).

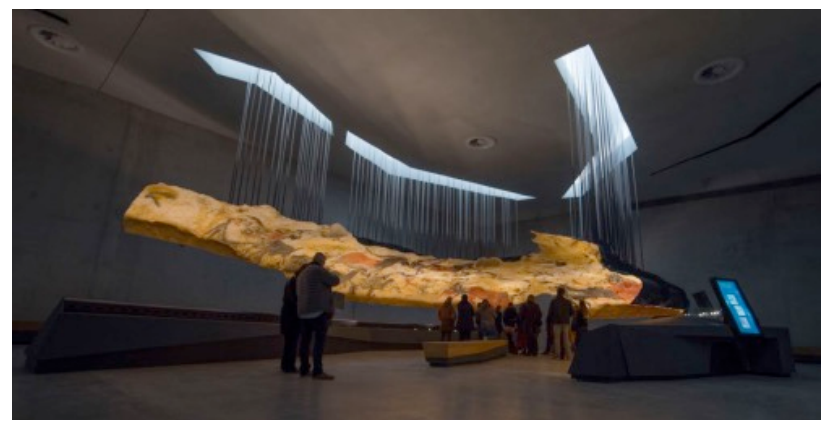

Figure 3. View of the Lascaux IV project

(https://www.lascaux.fr/fr/preparez-votre-visite/visitezlascaux/centre-international-art-parietal).

\subsection{Virtual and Augmented Reality}

Among the numerous virtual and augmented reality projects, we wish to point out the application developed in the castle of Vianden. The ArcTron 3D8 company has developed an augmented reality project for the site called "Virtual Vianden Box" or also "ViViBox" (see figure 4). The project was exhibited in 2018 at the ICT Spring Europe 2018 fair and is presented as a black box inside which users can operate their mobile phones to access additional 3D information about Vianden Castle. Visitors can view scenes from the daily life of the castle master and the castle itself during the various reconstruction phases. The aim is to travel around the country with this box to make people want to visit Vianden Castle in physical reality.

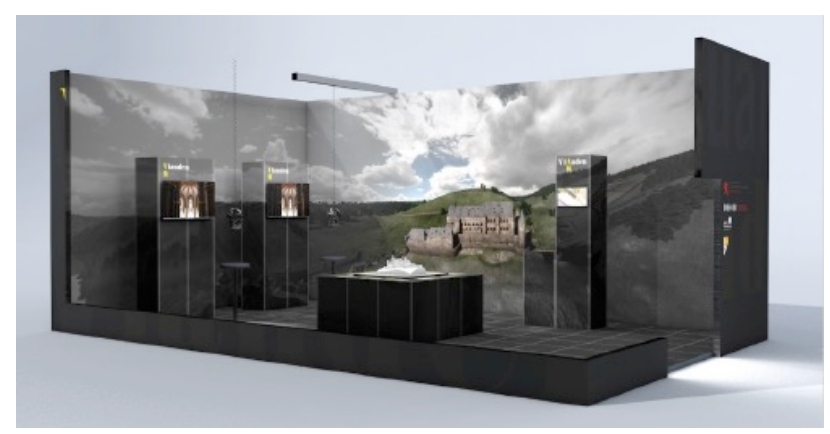

Figure 4. View of the ViviBox Project (https://www.arctron.de/references/2018-en/virtual-viandenbox-en/).

\subsection{Small-scale model}

Although an ancient tool in the mediation of heritage, small-scale models represent an indispensable tool in many situations. Nowadays, they are often combined with augmented reality applications. We present here a classical application allowing a significant diffusion of the tool. Dufaÿ and Mora discuss models in a feedback paper on digital technologies (Dufay \& Mora, 2013). They show that digital technologies are not always well used, pointing out the Royal Fortress of Chinon. A survey carried out in 2017 by Louise Léger (as part of her master's degree in Médiation et Valorisation du Patrimoine) shows that most visitors think that technology plays too important a role in their visit. They only spent a few minutes on the interactive terminals, and barely half were interested in how the 3D model of the fortress worked. However, the physical models initially intended for the visually impaired (see figure 5) attracted many visitors. These "tactile models" were developed by the company $\mathrm{CH}$ Maquettiste. Models are accompanied by a Braille legend and different textures to facilitate understanding.

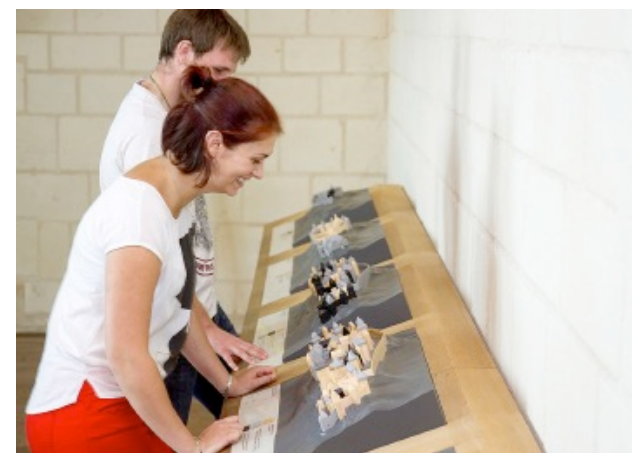

Figure 5. Model of the Royal Fortress of Chinon dedicated to visually impaired visitors (https://www.chmaquettiste.com/maquette-museographie-maquettes-tactiles).

\subsection{Cover sheet for a building}

This mean of communication (Figure 6) is different from the others because it is entirely external and directly related to the building. Therefore, it can reach a maximum number of people because designed covers are often placed in busy or high-traffic areas. In addition, during restoration work, scaffolding and protective sheeting surround the building, obscuring its façade. Therefore, it creates an opportunity to print a design on the covering sheet. Usually, this is a photo of the building's façade, but there are other possibilities. 


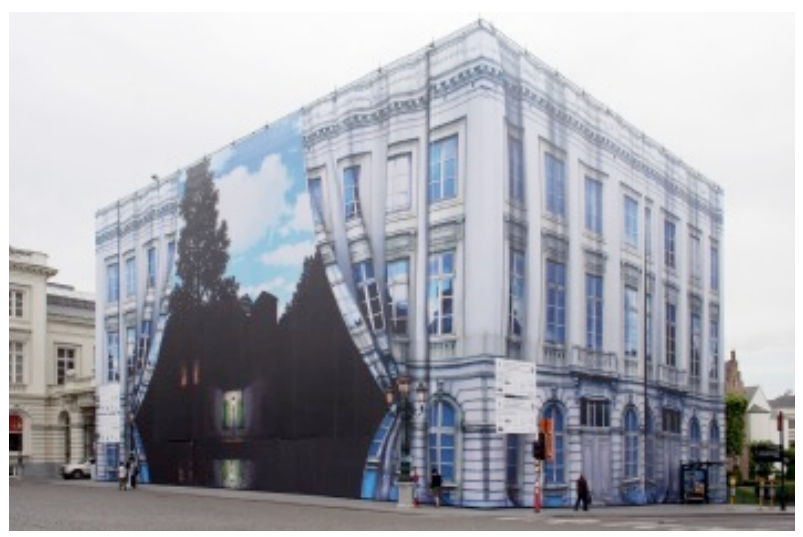

Figure 6. Cover sheet placed over the Magritte Museum (https://www.regiedergebouwen.be/nl/projects/magrittemuseum).

This paper uses the framework of Phygital Heritage applied to heritage communication of inaccessible places. We think that the phygital classification can provide a suitable solution in combining several communication tools to maintain or strengthen the link between heritage places and people.

To do so, we worked on the non-exhaustive classification of communication tools proposed in the Phygital Heritage model proposed by Nofal (Nofal et al., 2017). Initially intended to be applied in museum mediation, we discuss its extension to heritage communication frequently used in conservation as printing covers for restoration scaffolding. The research is implemented in the case of the St Croix Collegiate church of Liège, Belgium. A consequent phase of restoration of the building has just started, and it is planned to last for at least ten years. Through a combination of multiple heritage communication tools, we aim to keep a strong relationship between the public and the heritage building. A focus will be given on the design of the covering sheet application.

\section{HERITAGE COMMUNICATION SCHEME FOR INACCESSIBLE PLACES}

The communication about heritage buildings under restoration is specific. Indeed, there is a strong need to maintain a link between current and future visitors and the edifice. However, depending on the duration of the work, this link can fade. Some people can even forget what led to motivating the conservation project. Usually, heritage communication of inaccessible places is organized to be performed remotely. In these cases, the inaccessibility is either due to travel restriction, conflicts, or the deterioration of the site itself. Therefore, the communication of a building under restoration differs from such cases and should be approached from a different angle. For instance, the location of the Collegiate Church of the Holy Cross means that it is close to most of the public and its future users. Despite the numerous communication activities organized around the funding of the restoration and the new targeted uses of the building, the discussions carried out with visitors and locals surprisingly revealed that most of them did not even know the location of the church in the centre of Liege.

A paradox arises that requires communication closely related to the location of the site concerned and the fact that the latter is not accessible. Moreover, the surroundings of the worksite are frequently inaccessible too. Finally, the communication cannot be limited to an on-site proposal since the public and visitors deserve to be informed about all valuable features linked to the place, including those located in interior spaces. It shows how closely related the heritage communication is with the audience, the message, and the affordance of the tools (as described by Nofal). For this reason, we based our approach on the Phygital Heritage classification, and we tested if it could be compatible with new communication tools identified for inaccessible places. Although the Phygital Heritage model seems to be instead thought of to evaluate the pertinence of ICT tools implemented in a museum context, we believe the two aspects identified by Nofal are essential factors to consider when choosing the appropriate medium to communicate about such sites. Many aspects play a role in the communication or mediation of heritage places ranging from the objectives pursued, the available resources, the targeted audiences to the temporality of inaccessibility, the scale, the specific configuration, and the context of the concerned places. Hopefully, such a classification system enables situating various communication tools and techniques and facilitates their comparison. Additionally, in the framework of a project aiming to communicate explicit knowledge about different meanings of a place and the variety of values associated with it by society, this model helps to define the pertinence of communication tools from an educational point of view.

To structure the analysis, we propose considering three audience groups: "on-site audience," "remote audience," and "temporary visitors." The "on-site audience" group is defined as the people who live locally from the building. The group does not focus a priori on the building's heritage aspect. This feeling is exacerbated when the site is not visible due to the working installation: the barriers, the scaffolding trend mask the view to the site. The "remote audience" group gathers people interested in the heritage site but cannot travel there. The latter group of "temporary visitors" is defined as people who came on-site for a limited period. Temporary visitors do not live around the site. We assumed that this audience performs a one-shot visit. They can be living in the surroundings or be tourists.

The three defined classes are placed in the Phygital classification based on our vision of an adequate communication scheme (see Figure 7). Due to the nature of external visitors, the remote audience requires a digital communication tool that is not situated.

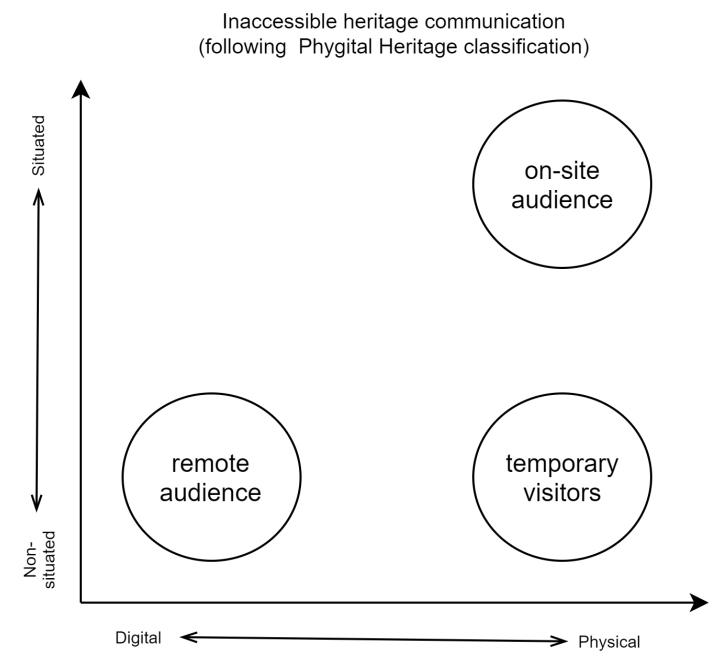

Figure 7. Audience classification based on Phygital Heritage framework. Each audience requires a dedicated communication tool.

Usually, the temporary visitors require a digital situated or nonsituated tool to afford a better heritage information transmission. 
In our case, it is not possible to propose access to the site to support a digitally situated mediation. It would also be possible to propose some augmented reality application which is a digitally situated mediation. However, we believe that the development costs and the installation complexity for a limited period make this solution unsuitable. It leads to consider the temporary visitors to require a physical and non-situated communication tool.

On the other hand, the on-site audience requires a permanent information tool. The communication solution must propose, in a playful way, information to an audience who does not necessarily ask for it. We do not follow the Phygital Heritage model in this case. Indeed, the device cannot be actuated due to the nature of the audience.

Such an approach aims to move the audience from one group to another, starting from the remote to the on-site. The temporary visitor's groups can benefit from the tools set up for the on-site audience. However, creating groups is more about the kind of heritage communication tool to design. Considering that the restoration projects require documenting heritage sites and buildings, the proposed tools can benefit from existing information. Indeed, reliable and precise communication about heritage is rarely considered in the financial plan for restoration. The reuse of previously collected datasets is therefore beneficial. We identified an open set of tools that gathers the criteria exposed previously and can serve as mediation tools for inaccessible places in the context of restoration. These tools are located on the Phygital Heritage classification. It appears that the augmented, integrated, and actuated division is no longer suitable for such an approach. The integrated division should be extended, and the actuated decreased to exclude some physical and situated tools.

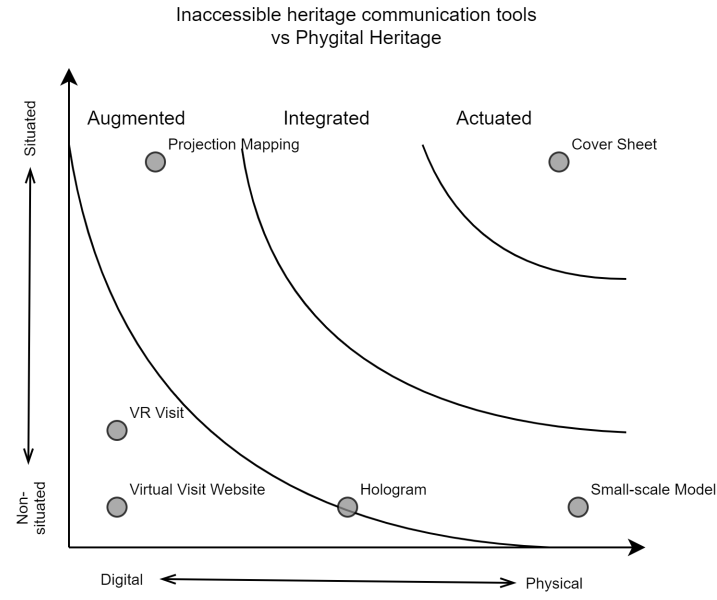

Figure 8. Inaccessible heritage communication tools in regard to the Phygital Heritage model.

We do not think that the model requires a new version. Instead, we aim to propose a more general use of the tool to help stakeholders organizing heritage communication. The costs and the information required by all the presented tools show that it is mandatory to consider the mediation concurrently with the restoration process. Even if they are designed for a temporary period, some of the proposed tools can be a basis for permanent mediation tools.

\section{APPLICATION ON THE REMARKABLE BUILDING OF COLLEGIALE SAINTE-CROIX}

Three applications are mainly detailed in the project, the realization of a virtual environment allowing the visit of the collegiate church Sainte Croix in its current state; a reproduction of the building on an external cover sheet supported by the scaffolding; a 3D production of an artefact via plastic printing.

\subsection{Information - building documentation}

Thanks to the Public Services of Wallonia and Jean-Noël Anslijn, we benefit from a complete 3D scan of the church. This highly detailed point cloud of several billions of coloured points serves as a basis for all the 3D applications. Unfortunately, due to the poor state of the building, scaffolding was erected around the building for several years. This construction complicated the survey. The point cloud contains all this information that makes the dataset unsuitable for producing external elevation. We performed other dedicated surveys at the beginning of the restoration process, specifically for some salient parts of the edifice inaccessible at the early stages of the works. Dozens of 360 degrees panoramic images have been acquired in each place (safely accessible). Figure 9 shows a subset of the raw point cloud dataset. The data required a lot of cleaning, colour adjustments to achieve the quality required for orthophoto production.

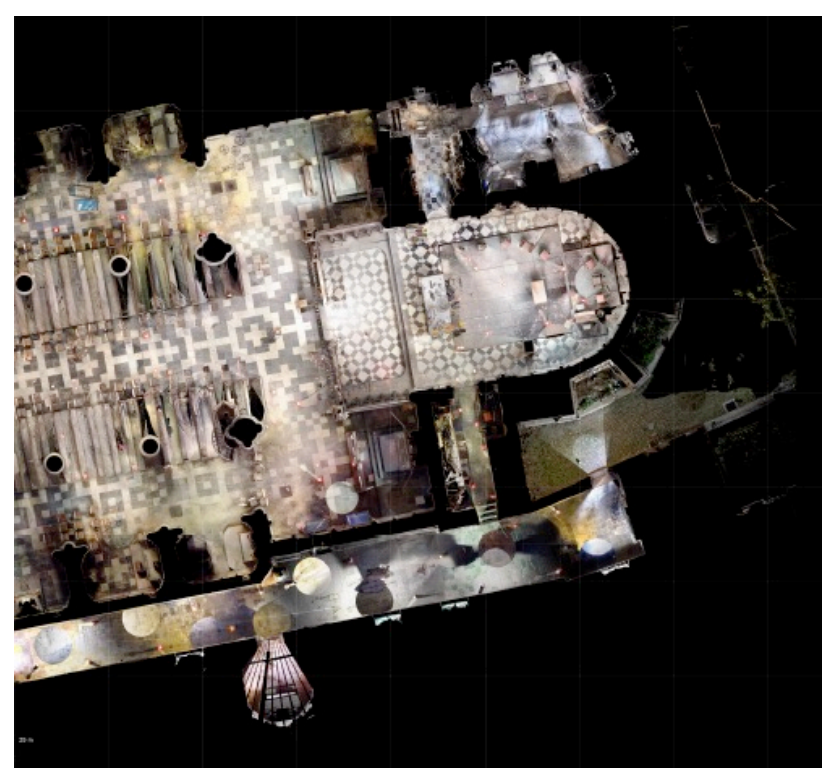

Figure 9. A subset of the point cloud of the collegiate Sainte Croix church.

\subsection{Website for remote audience}

We developed a website dedicated to a virtual visit of the inside of the church (Figure 10). This development was critical because of the previous inaccessibility of the place. Most of the audience does not even remember the interior of the edifice as it was closed for several years. Some sporadic visits were organized during the Heritages days. The website allows visiting the place from multiple determined points of view by teleportation. The tool is also accessible for users with a cardboard device, allowing a more immersive experience. It is worth mentioning that the visit includes places which were not accessible at regular times. Some of the panoramic images are taken from the roofs or on the top of the old scaffoldings.

The images have been taken specifically for the website. However, it is worth mentioning that the laser scan bubble images could be reused for this application, limiting the acquisition costs. 


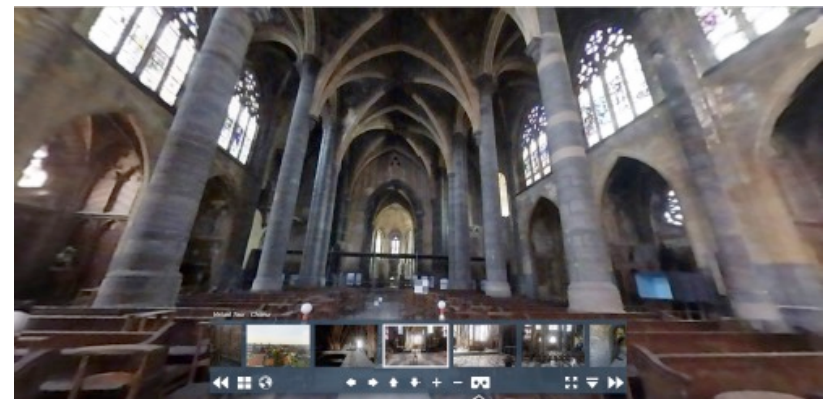

Figure 10. A subset of the point cloud of the collegiate Sainte Croix church.

\subsection{Small-scale model for temporary visitor audience}

Considering the temporary visitors, we opted for a souvenir that can be carried back home. The historical structure of the church is not usual. The storytelling includes this aspect in the mediation. From the point cloud, we reduced the model drastically to rebuild a meshed 3D model. To communicate about the structure of the church, it was decided to print a first model with only half of the building with the section plane aligned on its central-longitudinal axis (East-West, looking South). The model integrates information about the internal and roof structure (see Figure 11).

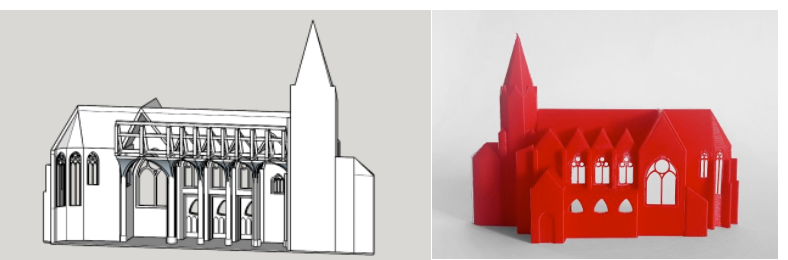

Figure 11. A subset of the point cloud of the collegiate Sainte Croix church.

Another production of the complete building has been made as a keyholder. The latter is projected to be given as souvenirs. For now, they are not yet available as far as the works only begin. We plan to extend this concept to the entire network of collegiate churches of the city of Liège.

\subsection{Cover sheet for on-site audience}

The main contribution to the mediation tools is undoubtedly the design of the scaffolding's cover sheet. This way of communication is situated on the building and produced from digital information. Usually, the designs give ideas of the final aspect of the project. In our case, we aim to link the audience with the inside ambience of the church. Furthermore, the recurrent visibility with the inaccessible interior of the building should strengthen the link with the emotive and associative values attached to it. Therefore, the first step of the production has been to study the best viewpoint for the design. Naturally, the place of the scaffolding is a constraint that cannot be changed. However, we considered the surroundings to calculate which part of the walls was visible from the main busy streets to reach more people (see Figure 12).

From the point cloud, we cleaned the furniture and the spheres used for adjustments. Then we generated several orthophotos for each plane of depths in the main neve and the roof. We assemble the images in managing each plane's exposition to give a visual effect of depth. The survey has highlighted the contours of the structure. Due to the darkness of the roof structure, the cloud was collected only with the intensities. For this reason, we decided to draw the structure. This approach ensures better readability for the elements and avoids a noisy view of all the beams. Finally, the stained glass has been replaced in the orthophotos with photography taken at night to highlight the colours and avoid reflectance in the scan views.

The image is produced with a 1:1 scale, which allows viewing a very high level of detail. As a result, the readability of the interior of the church will be guaranteed from a long distance. The final product is presented in Figure 12. Due to some delays with the pandemic, the scaffolding was placed during the spring and summer of 2020. The cover sheet will be printed and installed in October 2021. Some prints trials were made to ensure the readability and choice of the best resolution.
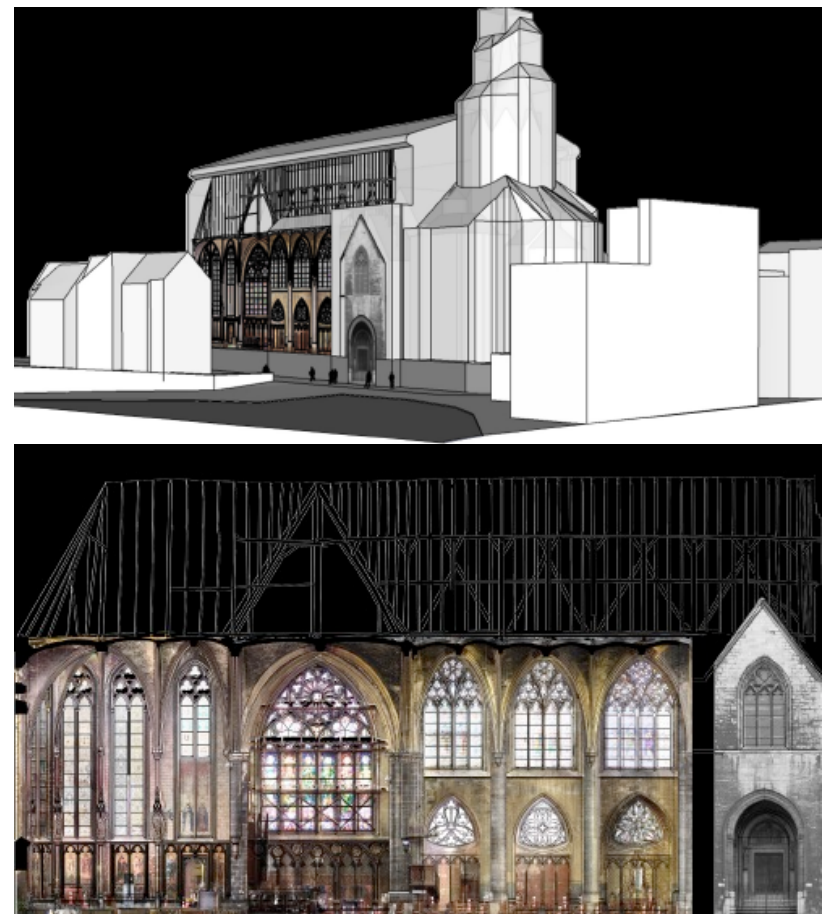

Figure 12. A subset of the point cloud of the collegiate Sainte Croix church.

\section{CONCLUSION AND PERSPECTIVES}

Communication about inaccessible buildings under restoration must be seen as an integral part of the conservation project itself. Indeed, through several means of communication, it is possible to reach the largest possible audience. Moreover, the information disseminated will strengthen the public's links with the heritage from these regular contacts. It is in this respect that heritage will be seen as a field that needs all the attention.

In this article, we have seen that some classifications for thinking about heritage mediation tools can be extended and adapted to the case of inaccessible heritage. This type of heritage does not allow the use of the usual mediation tools. Moreover, we have shown that situations in which heritage is not visible (hidden under a cover sheet) can become an interesting situation for a wide diffusion of what it contains.

The use of the data collected in various ways for the conduct of perennial studies can also be used for mediation. Be aware, however, that it is necessary to adapt this collection to allow for its easy use. Once all three devices are publicly available, their impact and the amount of information they can convey will need to be verified. This essential step will allow us to refine the 
choices according to other situations and propose new ways to communicate the heritage elements.

\section{ACKNOWLEDGEMENT}

The authors warmly thank the architectural studios ASAA, PHD, Pallot for their collaboration within the project. We wish to point out Valentin Klingeleers, who helped a lot with the design of the cover sheet. The point cloud datasets have been used with the courtesy of the AWaP (Agence Wallone du Patrimoine) and the help of Jean-Noël Anslijn.

\section{REFERENCES}

Avrami, E., \& Mason, R. (2019). Mapping the issues of value. In E. Avrami, S. Macdonald, R. Mason, \& D. Myes (Eds.), Values in Heritage Management: Emerging Approaches and Research Directions (pp. 9-33). The Getty Conservation Institue.

Bader, A. P. (2015). A model for everyday experience of the built environment: The embodied perception of architecture. Journal of Architecture, 20(2), 244-267. https://doi.org/10.1080/13602365.2015.1026835

Barazzetti, L., Banfi, F., Brumana, R., Oreni, D., Previtali, M., \& Roncoroni, F. (2015). HBIM and augmented information: Towards a wider user community of image and rangebased reconstructions. International Archives of the Photogrammetry, Remote Sensing and Spatial Information Sciences - ISPRS Archives, 40(5W7). https://doi.org/10.5194/isprsarchives-XL-5-W7-35-2015

Brandi, C. (1963). Theory of Restoration. Firenze Nardini Editore.

Buckley, K. (2019). Heritage Work: Understanding the Values, Applying the Values. In E. Avrami, S. Macdonald, R. Mason, \& D. Myes (Eds.), Values in Heritage Management: Emerging Approaches and Research Directions (pp. 50-65). The Getty Conservation Institue.

Caspani, S., Brumana, R., Oreni, D., \& Previtali, M. (2017). Virtual museums as digital storytellers for dissemination of built environment: Possible narratives and outlooks for appealing and rich encounters with the past. International Archives of the Photogrammetry, Remote Sensing and Spatial Information Sciences - ISPRS Archives, 42(2W5), 113-119. https://doi.org/10.5194/isprs-archives-XLII-2W5-113-2017

Choay, F. (1999). L'allégorie du patrimoine. Paris: Seuil.

de la Torre, M. (2013). Values and Heritage Conservation. Heritage \& Society, 6(2), 155-166. https://doi.org/10.1179/2159032x13z.00000000011

Dufay, B., \& Mora, P. (2013). Les restitutions 3D du prieuré Saint-Cosme (La Riche-Indre-et-Loire). La modélisation d'un ensemble complexe à plusieurs phases chronologiques. Virtual Retrospect, 6, 135-143.

Evrard, Y. (1997). Democratizing Culture or Cultural Democracy? The Journal of Arts Management, Law, and Society, 27(3), 167-175. https://doi.org/10.1080/10632929709596961

Garcia-Fernandez, J., \& Medeiros, L. (2019). Cultural Heritage and Communication through Simulation Videogames-A Validation of Minecraft. Heritage, 2(3), 2262-2274. https://doi.org/10.3390/heritage2030138

Gattinger, M., \& Whitehorse, Y. (2011). Democratization of culture, cultural democracy and governance. Canadian Public Arts Funders, 1-7.

Hausmann, A., \& Weuster, L. (2017). Journal of Heritage Tourism Possible marketing tools for heritage tourism: the potential of implementing information and communication technology. Taylor \& Francis, 13(3), 273-284. https://doi.org/10.1080/1743873X.2017.1334786

Lambert, M. (2020). "La communication du patrimoine inaccessible: étude de cas sur la collégiale Sainte-Croix." University of Liège.

Nofal, E., Reffat, R., Boschloos, V., Hameeuw, H., \& Moere, A. (2018). The Role of Tangible Interaction to Communicate Tacit Knowledge of Built Heritage. Heritage, 1(2), 414436. https://doi.org/10.3390/heritage1020028

Nofal, E., Reffat, R. M., \& Moere, A. Vande. (2017). Phygital Heritage: an Approach for Heritage Communication. Online Proceedings from the Third Immersive Learning Research Network Conference, July, 220-229. https://doi.org/10.3217/978-3-85125-530-0-36

Pantano, E., \& Tavernise, A.-. (2009). Learning cultural heritage through information and communication technologies: a case study. Journal of Information Communication, 3(1), $68-87$.

Piavaux, M. (2002). L'Église Sainte-Croix à Liège: Un monument à la croisée des apprentissages. In ICOMOS (Ed.), Estrategias relativas al patrimonio cultural mundial. La salvaguarda en un mundo globalizado. Principios, practicas y perspectivas. 13th ICOMOS General Assembly and Scientific Symposium. (pp. 290292). Icomos.

Pybus, C., Graham, K., Doherty, J., Arellano, N., \& Fai, S. (2019). NEW REALITIES FOR CANADA'S PARLIAMENT: A WORKFLOW FOR PREPARING HERITAGE BIM FOR GAME ENGINES AND VIRTUAL REALITY. International Archives of the Photogrammetry, Remote Sensing and Spatial Information Sciences - ISPRS Archives, 42(2/W15), 945952. https://doi.org/10.5194/isprs-archives-XLII-2-W15945-2019

Weissberg, J.-L. (1999). Le déplacement virtuel de Lascaux. In Public, nouvelles technologies, musées (Publics \&, Issue 13, pp. 129-145). Presses Universitaires Lyon. 